\title{
PESQUISAR E FORMAR: REPENSAR O LUGAR E A FUNÇÃO DA PRÁTICA DE ENSINO
}

\author{
YVES LENOIR*
}

\begin{abstract}
RESUMO: O presente artigo trata das relações entre pesquisa, prática e formação de professores. Após recapitular as críticas sofridas pela pesquisa em educação, o texto sublinha a especificidade da pesquisa científica, suas características, seus componentes estruturais e suas funções como processo de objetivação cognitiva. A distinção entre métodos e metodologia é abordada em seguida, colocando em evidência a necessidade de recorrer aos métodos mistos para analisar as práticas docentes e para considerar o processo científico a partir de uma estruturação quadripolar. Finalmente, as relações entre pesquisa e prática são consideradas em razão da formação docente.

Palavras-chave: Pesquisa. Prática. Formação docente. Processo de objetivação científica.
\end{abstract}

\section{RESEARCH AND EDUCATION: RETHINKING THE POSITION AND FUNCTION OF TEACHING PRACTICES}

ABSTRACT: The present paper deals with the links between research, education and practice. After having reminded the criticism to which research in education has been subjected, it points out the specificity of scientific research, its characteristics, its structural components and its functions as a cognitive objectivation process. The issue of distinguishing between methods and methodology is then examined, so as to enhance the need to resort to combined methods to analyse the teaching practices, and to stress the necessity of considering the scientific approach from a fourpole-structure. Finally, the relationships between research and practices are explored in regard to teacher education.

Key words: Research. Practice. Teacher education. Scientific objectivation process.

\footnotetext{
* Doutor em sociologia pela Universidade Paris 7, professor titular da Faculdade de Educação da Universidade de Sherbrooke e titular da Cátedra de Pesquisa do Canadá sobre Intervenção Educativa. E-mail: y.lenoir@videotron.ca
}

Educ. Soc., Campinas, vol. 27, n. 97, p. 1299-1325, set./dez. 2006

Disponível em <http://www.cedes.unicamp.br> 
Pesquisar e formar: repensar o lugar e a função da prática de ensino

\section{Introdução ${ }^{1}$}

ue Rutebeuf, grande poeta lírico parisiense do século XIII
$(1230-1285$ aproximadamente), perdoe-nos por ter copiado seu
Complainte: ${ }^{2}$

O que se tornaram meus amigos

Que eu tanto tinha cultivado

E tanto amado?

Acredito que eles estejam muito distantes

(...)

Acredito que o vento os levou de mim.

O amor está morto:

São amigos que o vento importa,

Ventava à minha porta

Os importa (...).

Refletindo sobre a relação entre pesquisa, prática e formação, este poema de Rutebeuf, que interpretava com tanta paixão Léo Ferré, veionos à memória para poder anunciar o nosso propósito aqui neste texto, em termos de reflexôes sobre os fios que se tecem entre pesquisa, prática e formação.

Em um primeiro momento, abordaremos o quanto a pesquisa em educação foi estigmatizada e acusada de impertinente. No entanto, os males pelos quais ela foi responsabilizada não resultam unicamente de problemas intrínsecos à pesquisa. Como nós o revelaremos suscintamente, em um segundo momento, outros fatores podem igualmente ser associados aos problemas observados. Em um terceiro momento, nos consacraremos à definição de pesquisa para clarificar seus diferentes significados e para precisar os principais atributos da pesquisa científica assim como as funções do processo de objetivação científica que permite a construção da realidade humana, social e natural. Em seguida, num quarto momento, colocaremos em destaque a importância de uma complementaridade entre os métodos qualitativos e quantitativos (métodos mistos). Precisaremos certas particularidades da distinção entre métodos e metodologia, invocando uma estrutura quadripolar e citaremos os componentes estruturais de uma pesquisa científica. Finalmente, em um quinto momento, nós trataremos das relaçôes indispensáveis entre pes- 
quisa, formação e prática, destacando, entre outros aspectos, as três funções da pesquisa sobre as práticas docentes e a necessidade que se coloca à pesquisa de objetivar uma modelização dessas práticas.

\section{A pesquisa em educação sempre problemática}

Atualmente, há um grande consenso quanto à condição indispensável de que a pesquisa em educação esteja refletida nas práticas de formação docente. Isso significa, se entendermos bem o duplo sentido do verbo refletir, que a pesquisa tem um impacto sobre as práticas de formação e estas em contrapartida influenciam os processos de pesquisa. Isso não parece ter sido assim sempre tão evidente. Comecemos por obscurecer o quadro.

\section{A pesquisa em educação fortemente criticada}

Nos Estados Unidos, o relatório do Holmes Group de 1990 assinalava que a pesquisa universitária "criou um hiato entre pesquisadores e professores levando à deformação destes últimos" (p. 57). Torbert (1981, apud Gélinas \& Pilon, 1994) questionava-se, já no início dos anos de 1980, por que a pesquisa em educação tem sido assim tão deseducativa. Alguns anos mais tarde, Kaestle (1993) afirmava que a pesquisa em educação sofre de uma reputação assustadora. Gélinas \& Pilon (1994) relembram que "Glasser, Abelson e Garrison (1983) recensearam e analisaram mais de duas mil publicações que tratavam da divergência entre pesquisa e prática" e mencionam que "vários autores destacam os limites, talvez mesmo o fracasso, da pesquisa científica, tanto fundamental quanto aplicada, para a tranformação de uma situação particular no meio escolar" (Gélinas \& Pilon, 1994, p. 76).

Resumidamente, além das visões catastróficas, apresentadas por vários pesquisadores que se dedicam ao estudo de diferentes ângulos das práticas profissionais, os modelos de pesquisa predominantes - sem negligenciar seus méritos - não podem responder adequadamente às questôes cada dia mais desafiadoras que um tal objeto impõe, seja no ensino ou na formação para o ensino.

Se Crahay (1989), ao retomar os trabalhos de Cuban (1984) e de Gage (1986), coloca em evidência os impactos limitados das inter- 
venções habituais para a modificação da prática dos professores e se ele constata, no que diz respeito à Europa francófona, que em 1990 se ensina ainda como no século XVIII, Doyle (1986), por sua vez, "defende a idéia de que os problemas de produtividade, de métodos e de teorias persistentes seriam atribuídos aos postulados que inspiraram as pesquisas do passado" (Doyle, 1986, p. 436).

\section{Alguns fatores explicativos}

Sem contradizer a importância de um tal fator, ele não pode explicar por si as carências que sofrem a pesquisa em educação, a prática docente e as relações entre pesquisa, formação e prática. Em nossa opinião, vários outros fatores, internos e externos, relevantes tanto do meio da pesquisa quanto do meio da formação e do meio da prática, devem ser levados em consideração. Sem pretensão de estabelecer uma classificação hierárquica, vejamos alguns exemplos a título ilustrativo: o peso da tradição; a resistência à mudança; as crenças culturais; a predominância dos processos de transmissão sobre os processos de produção do saber; a liberdade de escolha dos professores; a estrutura organizacional (organização do espaço, organização do tempo, modalidades de avaliação, amplitude e delimitação dos conteúdos etc.); o peso da modelagem no processo de formação; a falta de acompanhamento das práticas; os modelos de formação que separam a formação teórica da formação na prática; os professores universitários; os supervisores de estágios e os professores que acolhem os estagiários; as dificuldades das parcerias, a relação ao tempo sempre problemática; a existência da relação de poder freqüentemente oculta; os recursos humanos pouco disponíveis e os recursos financeiros raros e insuficientes; a dispersão dos pesquisadores e o pouco apoio aos muito raros centros de pesquisa; e, claro, a falta de leitura das obras científicas em educação por parte dos diferentes atores.

\section{O que deve ser entendido por pesquisa?}

Atualmente, existem vários caminhos que visam a ligar pesquisa e prática de formação à prática docente. Entre esses caminhos, a pesquisa colaborativa parece ser uma das vias mais interessantes (Desgagné, 1997, 1998; Desgagné et al., 2001; Lenoir, 1991, 1996). Para que a pesquisa possa se refletir (nos dois sentidos do termo "refletir" vistos 
anteriormente) nas práticas docentes de formação, será necessário voltarmos antes de mais nada ao significado do termo "pesquisa".

Redigindo com Sabine Vanhulle, atualmente professora na Universidade de Genebra, um livro sobre o estado da arte da pesquisa em formação docente no Québec, foi necessário esclarecer o que a palavra "pesquisa" significa de um ponto de vista científico em educação. Depois de termos procedido a uma leitura de aproximadamente uma centena de artigos e livros sobre a questão no campo da educação, nós chegamos à seguinte constatação.

\section{Procurar e pesquisar}

Primeiramente, é necessário estabelecermos uma distinção entre procurar e pesquisar. Eu posso procurar meu carro no estacionamento, a saída de uma grande loja, minhas chaves em casa ou em minha bolsa, meus amigos em uma multidão. Procurar, do latim procurare, significa a ação, o esforço para achar ou descobrir alguma coisa. A palavra "pesquisar", quanto a ela, coloca em evidência duas dimensôes fundamentais que devem acompanhar uma investigação sistemática: o trabalho de reflexão e o esforço de investimento que requer uma pesquisa.

\section{Estar em pesquisa}

Em segundo lugar, parece-nos necessário distinguir de um ponto de vista científico, assim como o fez Beillerot (1991), entre "estar em pesquisa" e "fazer pesquisa". Estar em pesquisa, precisa Beillerot, é refletir sobre problemas, sobre dificuldades encontradas; é se esforçar para descobrir respostas às questóes que nos colocamos. Trata-se, portanto, de um trabalho reflexivo sobre as atividades da nossa vida pessoal, social, familiar ou profissional. Em suma, trata-se de um trabalho reflexivo sobre nossas práticas, sobre nossas experiências. Reconhecemos atualmente que o processo de reflexão é um mecanismo de formação a privilegiar. A este respeito, Richardson (1994), citando House, Mathison \& McTaggart (1989), identifica três tipos de inferências às quais os professores se referem com frequiência:

(a) o pesquisador infere de um estudo avaliativo e espera que os professores o utilizem; (b) os professores inferem de um estudo avaliativo, mas modificam tais inferências em função do domínio particular de aplicação;

Educ. Soc., Campinas, vol. 27, n. 97, p. 1299-1325, set./dez. 2006

Disponível em <http://www.cedes.unicamp.br> 
(c) os professores inferem a partir de suas experiências pessoais e as aplicam em um dado contexto. (Richardson, 1994, p. 8)

Richardson argumenta que a pesquisa em educação tem ignorado enormemente o terceiro tipo de inferência. Este se mostra, portanto, como um dos mais importantes num processo de melhoria da prática profissional.

Mas sejamos claros, o agir humano repousa antes de mais nada no senso comum, que é ao mesmo tempo consciência prática e consciência intersubjetiva. O senso comum não tem nenhuma pretensão nem de proclamar a verdade, nem de promover a generalização, mas ele se insere em um nível de consciência imediata "a partir de sua fonte que pode ser a razão (no racionalismo) ou bem a experiência (no empirismo)" (Gueorguieva, 2004, p. 4). O senso comum insere-se na ação em busca de respostas apropriadas e eficazes a situações problemáticas levando em consideração diferentes opiniōes. Assim,

diferentemente da consciência científica (e filosófica) que tem como ideal a verdade indubitável, o senso comum é a cognição do agir, um tipo de consciência que se orienta rumo a um outro ideal de verdade completamente diferente do saber teórico, pois o senso comum é por natureza um saber prático, que pode em seguida ter uma aplicação no saber científico e filosófico: ele assegura o fundamento da consciência discursiva. (Gueorguieva, 2004, p. 6)

Dito brevemente, a lógica da pesquisa realizada pelo professor não está baseada nos mesmos parâmetros que alimentam a lógica do pesquisador. Como já foi explicado por Catz (1986) e Huberman e Gather Thurler (1991): os professores funcionam no "como" e não no "por quê".

\section{Fazer pesquisa}

Em terceiro lugar, fazer pesquisa de um ponto de vista científico repousa em outros alicerces, assim como mostra claramente Beillerot (1991, p. 19): "Fazer pesquisa implica outros processos, notavelmente aqueles que impóem o verbo 'fazer': encontrar os meios de uma objetivação das questões e das preocupações para poder estudá-los". Nesta perspectiva de processo de produção, Beillerot propõe inicialmente uma definição mínima da pesquisa, o que nós podemos classificar de pesquisa "de primeiro grau". Um processo de pesquisa implica três condições fundamentais: 
Yves Lenoir

- "uma produção de novos conhecimentos (critério n 1 );

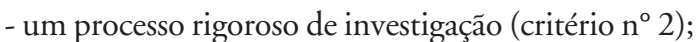

- a comunicação dos resultados (critério n ${ }^{\circ} 3$ )". (idem, ibid.)

Beillerot retoma assim a definição dada à ciência por De Bruyne (1988, p. 11):

entendida no sentido de pesquisa (Forschung) e não de saber (Wissenschaft), [a ciência] é um modo de produção de conhecimentos cuja finalidade principal é de explorar, de compreender e de explicar "o que é". A atividade científica se distingue dos outros modos de produção de conhecimento pela aquisiçâao de um certo tipo de saber (teórico) [critério no 1 ] e pela elaboração de certas normas ou procedimentos de investigação do real (lógica da descoberta), de validação dos resultados da pesquisa (lógica da prova) [critério no 2] e de comunicação desses resultados (lógica da exposição) [critério no 3 ].

Esta definição caminha no mesmo sentido das definições dadas por Legendre e por Lefrançois:

(...) conjunto de atividades metódicas, objetivas, rigorosas e verificáveis cujo objetivo é descobrir a lógica, a dinâmica ou a coerência num conjunto aparentemente aleatório ou caótico de dados, tendo em vista fornecer uma resposta inédita e explícita a um problema bem circunscrito ou contribuir ao desenvolvimento de um domínio de conhecimentos. (Legendre, 1993, p. 1.068)

A pesquisa científica (...) refere-se a todo trabalho sistemático e rigoroso ligando metodologia à problemática de estudo. Ela é a confrontação concreta entre os pressupostos teóricos e a realidade apreendida. (Lefrançois, 1992, p. 13)

Sigamos mais adiante! Beillerot (1991) identifica a existência de uma pesquisa "de segundo grau". Essa pesquisa requer a introdução de três novos critérios:

- a introdução de uma dimensão de crítica e de reflexão sobre suas fontes, seus métodos, seus modos de trabalho (critério $\mathrm{n}^{\circ}{ }^{4}$ );

- uma sistematização da coleta dos dados $\left(\right.$ critério n $^{\circ} 5$ );

- a presença de interpretações enunciadas segundo teorias reconhecidas e atuais que contribuam à elaboração de uma problemática e à interpretação dos dados (critério $\left.\mathrm{n}^{\circ} 6\right)$.

Assim, a pesquisa científica caracteriza-se como um processo de investigação que se destaca de outros processos de construção do saber. No fundo, esses três últimos critérios vêm qualificar o critério no 2 . O pro-

Educ. Soc., Campinas, vol. 27, n. 97, p. 1299-1325, set./dez. 2006

Disponível em <http://www.cedes.unicamp.br> 
cesso de pesquisa, como um processo rigoroso de investigação, deve ser crítico, reflexivo e responder às exigências das estratégias de verificação em uso. A teorização que resulta da pesquisa e que a sustenta deve estar relacionada a teorias reconhecidas. Entretanto, toda pesquisa que não responda aos três primeiros critérios não poderá ser reconhecida como uma pesquisa científica (Beillerot, 1991).

\section{As funções do processo de objetivação científica}

Em quarto lugar, a pesquisa científica requer a operacionalização das funções que caracterizam a ciência compreendida em sentido genérico. Como Freitag (1986) explica, nas suas dimensões gerais, como sistema formalizado, todo processo de objetivação - definido como processo humano constitutivo de um objeto (como processo cognitivo) ao qual é atribuído uma significação objetiva - implica a necessidade de recorrer, seja implicitamente como na consciência comum, seja explicitamente como é o caso na consciência científica, a três momentos funcionais, assim como o método cartesiano colocou em evidência e os desenvolveu:

- a função de construção operatória (ou de discriminação significativa) que circunscreve um objeto como um campo de análise (um plano operatório) potencialmente operacionalizável no que diz respeito aos planos simbólicos ou formais;

- a função de determinação ou de abstração objetiva que delimita o conjunto dos objetos significativos virtualmente identificados pela construção operatória e que dá a esses mesmos objetos uma consciência objetiva (uma estrutura), confrontando-os com o real por meio de manipulações empíricas;

- a função de imputação teórica objetiva ou de síntese teórica que atribui ao objeto empiricamente constituído uma especificidade no plano abstrato como uma realidade construída.

Assim, simplificando, nós poderíamos atribuir à função operatória a necessidade de determinar e construir o objeto de estudo como problema, à função empírica a coleta dos elementos para resolver um tal problema e à função teórica a produção formalizada do saber constituído.

Os três momentos fundamentais do método científico, assim diferenciados, não garantirão, portanto, o processo de objetivação nas práticas científicas enquanto eles não forem aplicados de forma que se estabeleça uma relação entre dois desses momentos, mediatizada pelo terceiro. É ne- 
cessário notar que várias correntes epistemológicas se inscrevem principalmente em uma perspectiva bipolar, excluindo assim uma de suas funções epistêmicas ou confundindo-a com uma das outras (Beillerot, 1991).

Mas essas três funções que definem a ciência em sua concepção clássica, tal como apresentada, entre outros, por Descartes (Lenoir, 1993) e pela corrente positivista, não são suficientes. É importante ultrapassar uma tal concepção do trabalho científico, adicionando a esta, numa perspectiva que se distancia do discurso do método catersiano para adotar a dialética do discurso hegeliano (Lenoir, 1993), as funções de valor e de sentindo. A função de valor "corresponde à dimensão cultural, além de exprimir uma certa relação com o mundo socialmente estruturado. Ela inscreve o processo de objetivação no real e projeta os limites do instrumento operatório sobre o real explorado" (Lenoir, 1993 , p. 57). Se a significação tem uma fonte que é o valor, a função de sentido vem (re)localizar concretamente essa fonte, torná-la dinâmica, substituindo-a em sua gênese. Ela vem situar numa perspectiva sócio-histórica o processo de objetivação científica e sua ancoragem, sua significação na realidade social.

A Figura 1 apresenta sinteticamente as relações entre as diferentes funções do processo de pesquisa científica.

Figura 1

As funções do processo científico

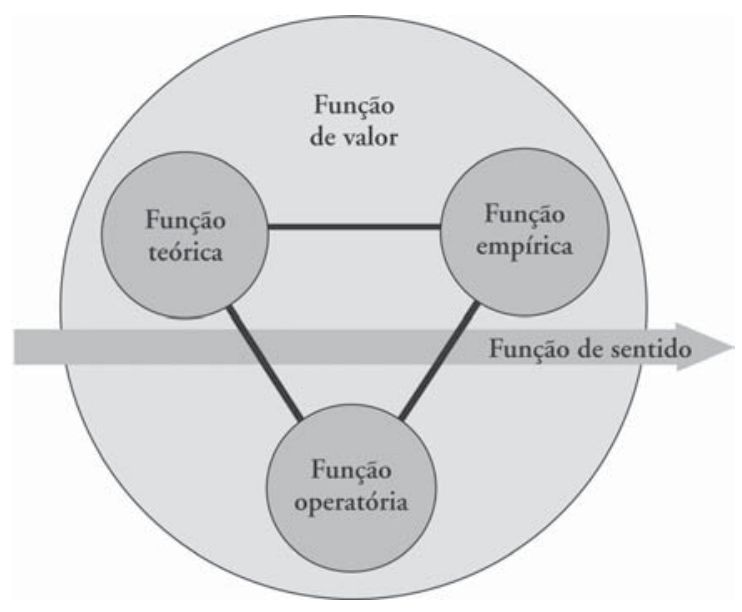

Educ. Soc., Campinas, vol. 27, n. 97, p. 1299-1325, set./dez. 2006

Disponível em <http://www.cedes.unicamp.br> 
Pesquisar e formar: repensar o lugar e a função da prática de ensino

Assim definido,

(...) o processo de objetivação é ao mesmo tempo um processo de construção do sujeito, que implica uma relação social, e um processo de construção da realidade objetiva à qual o sujeito reconhece pertencer e a partir da qual ele garante seu reconhecimento como sujeito humano. (Lenoir, 1993, p. 67)

Adicionemos ainda que

todo processo de objetivação cognitiva, do ponto de vista da dialética do real, se realiza em uma interação entre os três componentes de base seguintes:

$1^{\circ}$ ) o sujeito humano que produz o conhecimento do real e se transforma em conseqüência do processo cognitivo que realiza;

$2^{\circ}$ ) o objeto de conhecimento construído, circunscrito e definido como objeto de estudo desejado;

$3^{\circ}$ ) a relação cognitiva que se estabelece entre o sujeito e o objeto por intermédio de um sistema de regulação objetiva (a mediação), constitutivo de um e de outro, sendo o sujeito o elemento ativo da relação. (Lenoir, 1993, p. 68)

Métodos qualitativos, quantitativos e mistos: pelo fim do debate estéril

Em quinto lugar, no que diz respeito ao plano metodológico, assim como Hilda Borko (2004) acaba de nos relembrar ao se referir a uma posição tomada em janeiro de 2003 pela American Educational Research Association (AERA), existem numerosas abordagens metodológicas disponíveis no campo da educação e será importante trazer à tona que, para cada pesquisa, não são os métodos que devem estar em primeiro lugar, mas sim a questão de pesquisa, o quadro conceitual e os objetivos operatórios. $\mathrm{O}$ método, do grego meta, "em direção a", e hodos, "caminho", é o caminho a seguir para se chegar a um objetivo fixado anteriormente (pela questão de pesquisa). Mas esse caminho não é determinado a priori; ele é consequiência das escolhas problemáticas e também dos postulados, dos axiomas, das pressuposiçōes - que o sociólogo Gouldner (1971) chama de background assumptions -, que motivam o pesquisador em seu ponto de partida. Esse ponto de partida é de ordem ontológica, referindo-se a uma relação com o sujeito, de ordem epistemológica, referindo-se a uma relação com o saber, e de ordem axiológica, em referência a uma relação com o agir. 
Como várias publicações sobre a pesquisa demonstraram recentemente (Chi, 1997; Creswell, 2002; Johnson \& Onwuegbuzie, 2004; Shaffer \& Serlin, 2004; Tashakkori \& Teddlie, 1998, 2003), esta multiplicidade de vias potenciais no que diz respeito aos procedimentos de coleta e de análise dos dados evidencia a inutilidade do debate entre quantitativo e qualitativo e do discurso que defende sua incompatibilidade. Os tratamentos qualitativos e quantitativos - chamados também de métodos mistos - colocam em evidência a complementaridade enriquecedora entre esses dois tipos de métodos, utilizados segundo combinações seqüenciais ou em paralelo. Tashakkori \& Teddlie (1998), por exemplo, fizeram um levantamento de pesquisas que combinam os dados qualitativos aos quantitativos.

Eles descrevem como a análise quantitativa pode identificar questôes para o estudo qualitativo; como as entrevistas qualitativas podem oferecer uma clarificação a um processo de análise quantitativa; como a análise qualitativa pode gerar hipóteses para estudos quantitativos; e como dados qualitativos e quantitativos podem ser coletados simultaneamente. (Shaffer \& Serlin, 2004, p. 16)

Esses mesmos autores, antes de tentarem estabelecer uma co-existência independente de métodos quantitativos e qualitativos no interior de uma mesma pesquisa, recorrem a uma abordagem quantitativa baseada em uma análise estatística dos dados e apoiada diretamente por um tratamento qualitativo.

O uso de métodos mistos parece-nos ainda mais apropriado quando nos referimos ao estudo das práticas de ensino e das práticas de formação docente. Johnson e Onwuegbuzie (2004) realizaram uma análise comparativa dos métodos qualitativos e quantitativos colocando em destaque suas forças e suas fraquezas respectivas (Tabelas 1 e 2). Eles lembram igualmente que os principais atributos das pesquisas quntitativas são "a centração na dedução, a confirmação, a verificação de teorias e de hipóteses, a explicação, a predição, a coleta de dados estandardizados e a análise estatística" (Johnson \& Onwuegbuzie, 2004, p. 18). Quanto às pesquisas qualitativas, esses autores consideram que suas principais características são a "indução, a descoberta, a exploração, a produção de teorias e de hipóteses, a centração no pesquisador como primeiro 'instrumento' de coleta dos dados e a análise qualitativa” (idem, ibid.). 
Pesquisar e formar: repensar o lugar e a função da prática de ensino

\section{Tabela 1}

Elementos de comparação entre os métodos quantitativos e os métodos qualitativos: algumas forças respectivas

\begin{tabular}{|l|l|}
\hline \multicolumn{1}{|c|}{ Métodos quantitativos } & \multicolumn{1}{c|}{ Métodos qualitativos } \\
\hline $\begin{array}{l}\text { Verificação e validação sustentadas por quadros } \\
\text { conceituais ou teóricos }\end{array}$ & $\begin{array}{l}\text { Os dados são baseados em categorias de pensamento } \\
\text { dos participantes }\end{array}$ \\
\hline $\begin{array}{l}\text { Generalização dos resultados em função da } \\
\text { amostragem }\end{array}$ & Estudo profundo de um número limitado de casos \\
\hline Prediçães & Fácil descrição de fenômenos complexos \\
\hline Controle de variáveis & Rica descrição de fenômenos em seu contexto local \\
\hline Dados precisos, rapidamente coletados e analisados & Possibilidades de análise comparativa de casos \\
\hline $\begin{array}{l}\text { Independência relativa dos dados em relação ao } \\
\text { pesquisador }\end{array}$ & Dados coletados habitualmente em contexto natural \\
\hline Larga amostragem & Análises dinâmicas (ex. processo de construção) \\
\hline $\begin{array}{l}\text { Credibilidade elevada dos resultados junto aos } \\
\text { governantes e administradores políticos }\end{array}$ & $\begin{array}{l}\text { Possibilidade de identificar como o participante } \\
\text { interpreta os significados atribuídos aos dados }\end{array}$ \\
\hline
\end{tabular}

Tabela 2

Elementos de comparação entre os métodos quantitativos e os métodos qualitativos: algumas fraquezas respectivas

\begin{tabular}{|l|l|}
\hline \multicolumn{1}{|c|}{ Métodos quantitativos } & \multicolumn{1}{|c|}{ Métodos qualitativos } \\
\hline $\begin{array}{l}\text { As categorias utilizadas pelo pesquisador podem não } \\
\text { refletir a compreensão do meio estudado }\end{array}$ & $\begin{array}{l}\text { Impossibilidade frequente } \\
-\quad \text { de generalização } \\
-\quad \text { de transferência dos resultados } \\
-\quad \text { de predições } \\
-\quad \text { de verificar hipóteses e teorias }\end{array}$ \\
\hline $\begin{array}{l}\text { Esquecimento eventual do fenômeno ou incapacidade } \\
\text { de apreendê-lo }\end{array}$ & Credibilidade problemática dos resultados \\
\hline $\begin{array}{l}\text { O saber produzido pode ser demasiadamente abstrato } \\
\text { ou demasiadamente geral }\end{array}$ & $\begin{array}{l}\text { Necessidade de muito tempo para coletar e analisar os } \\
\text { resutlados }\end{array}$ \\
\hline $\begin{array}{l}\text { Teorias utilizadas às vezes de forma inadequada com } \\
\text { relação às compreensões locais }\end{array}$ & $\begin{array}{l}\text { Maior perigo de alteração dos resultados devido à } \\
\text { pouca distanciação do pesquisador }\end{array}$ \\
\hline
\end{tabular}

Em contrapartida, Ferréol \& Deubel (1993) são levados a confrontar os dois tipos de método do ponto de vista de suas exigências operacionais (Tabela 3), de maneira que se distingam as regras e as modalidades necessárias para operacionalizar o processo metodológico escolhido. 
Tabela 3

Elementos de comparação entre os métodos quantitativos e os métodos qualitativos segundo as exigências operacionais

\begin{tabular}{|c|c|}
\hline Abordagens quantitativas & Abordagens qualitativas \\
\hline $\begin{array}{cc}\text { Validade } & \\
- & \text { interna } \\
- & \text { externa }\end{array}$ & Credibilidade \\
\hline Fiabilidade & Transferência \\
\hline \multirow[t]{2}{*}{ Objetividade } & Consistência \\
\hline & Fiabilidade \\
\hline
\end{tabular}

Em síntese, Johnson \& Onwuegbuzie (2004) consideram que recorrer aos métodos mistos, em nome do paradigma metodológico que visa a superar as disputas intermináveis e a se centrar nas conseqüências empíricas e práticas, constitui uma abordagem pertinente. Sem entrar neste debate, nós consideramos que a análise das práticas docentes, em razão de suas características múltiplas e habitualmente complexas, deveria ser efetuada a partir de dispositivos e procedimentos de coleta e de tratamento de dados que levem em conta os métodos mistos.

\section{O método não pode se confundir com a metodologia}

Em sexto lugar, é importante diferenciar método e metodologia. Estes dois termos são, na maior parte do tempo, utilizados como sinônimos ou mesmo como equivalentes. Ora, se a produção do saber científico é um processo histórico e social, tanto em sua gênese como em sua organização, sua especificidade resulta de sua dinâmica interna, ou seja, da natureza de seu processo ou de sua metodologia geral. Para De Bruyne (1988), De Bruyne, Herman \& De Schoutheete (1974), assim como para Ferréol \& Deubel (1993), a metodologia da pesquisa

(...) reagrupa o conjunto das idéias diretrizes que orientam a investigação empírica. O conhecimento é assim entendido como um produto que é necessário testar ou validar (lógica da prova); como um processo cuja gênese deve ser reconstituída (lógica da descoberta). (Ferréol \& Deubel, 1993, p. 40) 
Pesquisar e formar: repensar o lugar e a função da prática de ensino

Para De Bruyne, Herman e De Schoutheete (1974, p. 34),

é possível identificar quatro pólos metodológicos no campo da prática científica: pólo epistemológico, pólo teórico, pólo morfológico e pólo técnico. Eles não constituem momentos separados da pesquisa, mas aspectos particulares de uma mesma realidade de produção de discursos e de práticas científicas.

\section{Os pólos da pesquisa científica}

A ciência em ação - a pesquisa ou o processo de objetivação científica - pode ser descrita como

(...) uma atividade metodológica que resulta da tensão dinâmica entre quatro pólos orientadores da pesquisa (...). Os quatro pólos não constituem momentos separados da pesquisa, mas aspectos particulares de uma mesma realidade de produção científica. Eles constituem um espaço metodológico no interior do qual diversas vias podem ser seguidas. (De Bruyne, 1988, p. 11-13)

Assim, como precisa De Bruyne (1988, p. 12),

(...) fora de sua função geral de reflexão e vigilância crítica sobre os modos de produção e de validação dos conhecimentos, o pólo epistemológico é responsável, ao longo da pesquisa, pela objetivação, isto é, pela elaboração do objeto científico e de sua tradução em uma linguagem científica, ou ainda pela ruptura entre um estado pré-científico e um estado científico do conhecimento. Assim, o objeto de pesquisa é construído como uma problemática que estimula todo o desenvolvimento científico sob a forma de questionamentos e exigências de solução.

Esta clarificação possibilita também evitar a confusão entre método e epistemologia, o que tem sido uma coisa freqüente segundo Johnson e Onwuegbuzie (2004), retomando as palavras de Bryman (1984) e Howe (1992). Quanto ao pólo teórico, ele

(...) apresenta dois aspectos indissociáveis, um aspecto conceitual de explicação do sentido no plano semântico e um aspecto proposicional de formulação coerente no plano da lógica. O processo de teorização conduz a hipóteses de trabalho que são soluções teóricas propostas aos problemas científicos levantados e que devem ser testadas, suscetíveis de serem submetidas à experimentação. (Johnson \& Onwuegbuzie, 2004, p. 12) 
Ferréol e Deubel (1993) destacam que o pólo teórico é o lugar da formulação sistemática dos objetos científicos: "A exigência de conceitualização se traduz, geralmente, pela construção de modelos" (p. 40). O terceiro pólo - o pólo morfológico - "articula os conceitos, as teorias e os modelos do objeto em esquemas ou em sistemas explicativos e interpretativos. Ele constitui também o quadro operatório da representação e da estruturação dos objetos científicos" (De Bruyne, 1988, p. 12). Ele "é a instância que enuncia as regras de estruturação e de formação do objeto científico e que impóe uma certa figura, uma certa ordem entre seus elementos" (De Bruyne, Herman \& De Schoutheete, 1974, p. 35). Enfim, o pólo técnico

(...) controla a coleta de dados, se esforça para constatá-los e confrontálos com a teoria que os suscitou. Ele exige precisão na constatação, mas ele não garante, por si, a exatidão. O pólo técnico tem à sua volta modos de investigação particulares, estudos de caso, estudos comparativos, experimentaçôes, simulações. (...) A interação dialética desses diferentes pólos constitui o conjunto da prática metodológica e esta concepção introduz um modelo topológico e não cronológico da pesquisa. (De Bruyne, Herman \& De Schoutheete, 1974, p. 35-36)

O pólo técnico diz respeito aos métodos de pesquisa, de coleta e de tratamento dos dados. Por método, como já mostrado em uma outra publicação (Lenoir, 1993), entendemos "o conjunto organizado de intervençōes refletidas buscadas pelo pensamento; intervençōes que partem de um objeto preciso a fim de alcançar, por meio de uma sucessão de etapas, o objetivo anteriormente determinado" (p. 48). A Figura 2 esquematiza esta estrutura quadripolar da prática de pesquisa científica de um ponto de vista metodológico.

\section{Os componentes estruturais da pesquisa científica em educação}

Em sétimo lugar, a análise crítica da documentação científica de língua francesa e inglesa sobre a pesquisa em educação que nós realizamos (Vanhulle \& Lenoir, 2005) revela que os autores consultados definem a pesquisa científica a partir das diferentes etapas com as quais eles estão familiarizados, a partir de suas opçōes epistemológicas ou ainda a partir de seus campos de interesse. Essa análise permitiu a identificação de oito componentes que caracterizam a pesquisa científica: um objeto de pesquisa, uma problemática, um quadro teórico ou conceitual, 
uma metodologia, uma coleta de dados, os resultados, uma análise e interpretação desses resultados e, finalmente, uma difusão dos saberes produzidos.

Figura 2

Estrutura quadripolar da prática metodológica

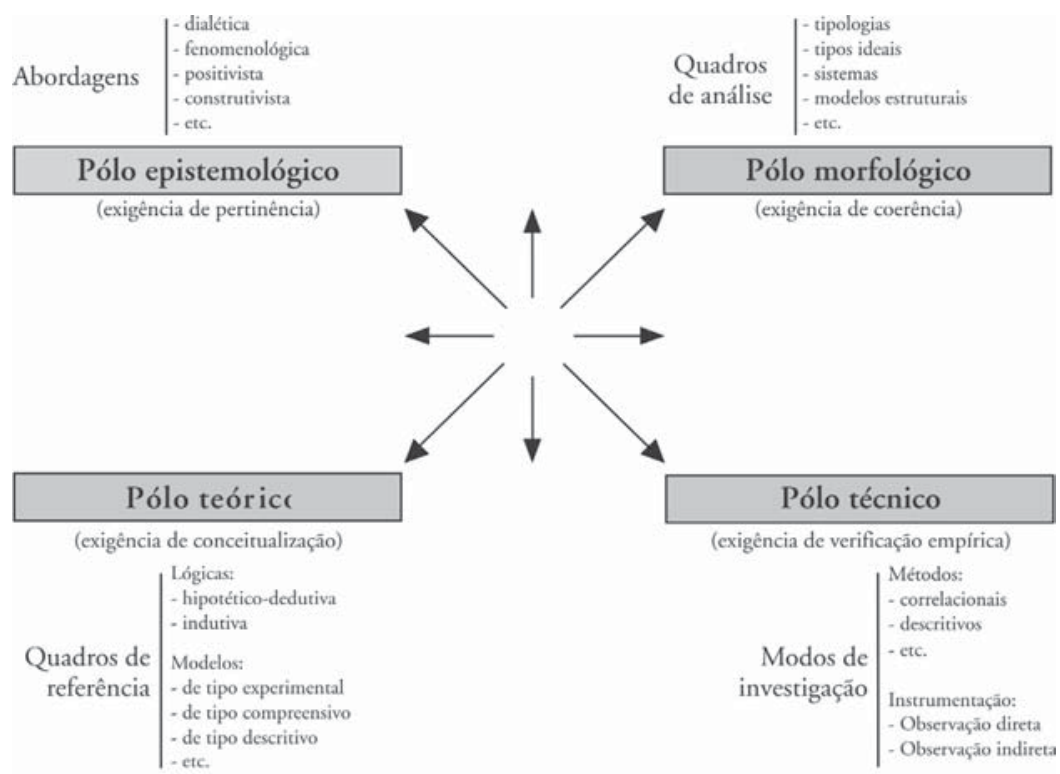

(Quase integralmente extraído de: De Bruyne, Herman e De Schoutheete, 1974)

As relações entre pesquisa, formação e prática

É necessário adicionar um nono componente relativo à transformação das práticas aos oito componentes supracitados, considerado essencial, entre outros, por Karsenti e Savoie-Zajc (2000). Esse nono componente se refere precisamente às funçóes de valor e de sentido mencionadas no início deste texto. Ele diz respeito igualmente à distinção já assinalada entre prática científica e razão prática. E então a questão da relação entre pesquisa, formação e prática se coloca. 
Figure 3

Componentes estruturais de uma pesquisa científica

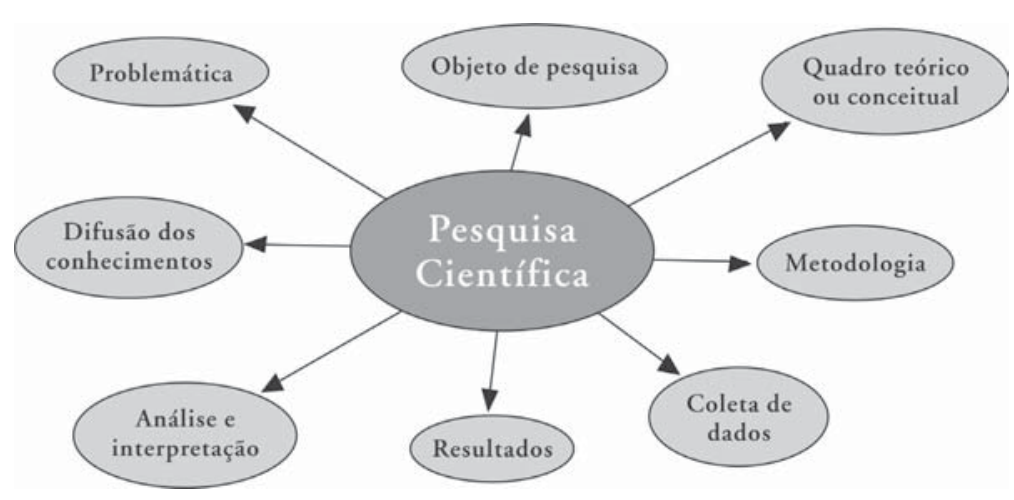

Inicialmente, é importante distinguir, como o fez Richardson (1994), a pesquisa formal (formal research) sobre as práticas da investigação prática (practical inquiry). Se essas duas formas de pesquisa não são incompatíveis no interior de diferentes tipos de pesquisa, como é o caso da pesquisa colaborativa, elas não podem entretanto ser confundidas se retornarmos aos seis critérios enunciados por Beillerot (1991). Além disso, esses dois tipos de pesquisa buscam finalidades diferentes. Se a investigação prática conduzida pelo professor durante suas atividades cotidianas visa essencialmente a mlhorar, a modificar suas práticas, a mais bem compreender seus alunos ou o contexto social para adaptar suas condutas, a pesquisa formal sobre o ensino, por sua especificidade, tem antes de mais nada uma visão cognitiva. Ela estuda os saberes dos professores, suas representações e outras construções ligadas à relação educativa e seus componentes, assim como suas ações em sala de aula e as transformações de suas condutas didáticas e pedagógicas. Encontramos a distinção precedente, estabelecida também por Beillerot (1991), entre "estar em pesquisa" e "fazer pesquisa".

As diferentes distinçôes que nós acabamos de mostrar nos conduzem a dizer algumas palavras sobre as finalidades da pesquisa sobre as práticas docentes. Por "práticas docentes" entendemos tanto as práticas dos professores quanto aquelas dos formadores de professores. 
Altet (2000), Bru (2002a) e Marcel et al. (2002) destacam a existência de três funções primordiais para o estudo das práticas: prescrever, formar e teorizar.

Em primeiro lugar, prescrever! A pesquisa científica possui uma função operatória a fim de garantir um maior domínio e uma maior eficiência da interveção educativa do professor, tanto no plano da formação inicial quanto no da continuada. Esta preocupação no que se refere à evolução das práticas docentes deveria permitir, como evidencia Bru (2002a), avaliar, comparar e identificar as modalidades mais diferenciadas da prática, guiar a ação dos formadores que intervêm junto dos professores para ajudá-los a tranformar suas práticas, para ajudá-los a explicitar os dados de um problema e contribuir à sua resolução, mas também para sustentar o processo de profissionalização da profissão docente.

Em segundo lugar, formar! A esta função de transformação e de evolução das práticas se associa "uma função de formação (centrada no desenvolvimento da experiência e na construção identitária)" (Marcel et al., 2002 p. 136). Sendo assim, é o desenvolvimento do profissional (a pessoa e o ator) que está no centro da abordagem das práticas. A este respeito, Huberman $(1989,1990)$ destaca a necessária interdependência entre a pesquisa e a difusão dos seus resultados, mostrando que o estabelecimento de relaçóes estreitas entre pesquisadores e professores ao longo de uma pesquisa constitui um forte indicador da utilização que estes últimos farão eventualmente dos resultados da pesquisa (Huberman, 1987). A importância de conceber a pesquisa e a formação numa perspectiva colaborativa revela-se essencial. Vários estudos já citados apresentaram os atributos e as contribuiçóes de um tal tipo de pesquisa.

Em terceiro lugar, teorizar! A pesquisa sobre as práticas docentes objetiva "a função heurística tradicional da pesquisa" (Marcel et al., 2002, p. 136). Ela possui uma função teórica (Altet, 2000), que visa a descrever, a compreender e, eventualmente, a explicar a organização das práticas (Bru, 2002b), isto é, a produzir novos saberes relativos às práticas, visando à produção de modelos ${ }^{3}$ de inteligibilidade das práticas observadas. Tais modelos poderão ser em seguida transferidos em objeto de formação.

Relembraremos ainda que Bayer (1986) mostrou que as pesquisas sobre as práticas docentes vêm há muito tempo se baseando em duas pistas tradicionais: por um lado, a pista das aplicaçóes, que se re- 
fere ao modelo da pedagogia experimental e que "define seus domínios de pesquisa somente a partir dos problemas concretos que vivem os responsáveis e os usuários da escola" (p. 484); e, por outro lado, a pista das recuperaçóes psicológicas pela entrada da psicologia na educação: "As situações pedagógicas são somente investigadas para experimentar e verificar teorias estrangeiras ao ensino" (ibid.).

Essas duas primeiras pistas já demostraram seus limites, como pôde ser constatado por Adey, 2004; Dunkin, 1986; Tardif et al., 2000. Ora, com o interesse dos pesquisadores naquilo que acontece em sala de aula, notam Baudouin \& Friedrich (2001), "um novo objeto de pesquisa começa a emergir. $\mathrm{O}$ olhar, fixado até então nos alunos e na maneira como o saber é ensinado e aprendido, é direcionado igualmente à análise sitemática da ação efetiva do professor" (p. 13). Tratase aqui de uma terceira pista de pesquisa que parece atualmente promissora: a pista que postula lógicas próprias às práticas docentes e que requer "a análise dos processos de ensino" (Bayer, 1986, p. 485). Para agir sobre as práticas, é necessário estudá-las na sua cotidianidade.

Mas, então, precrever, formar... O que dizer sobre isso? Munby, Russell e Martin (2001) assim como Spencer (2001) argumentam sobre o perigo e a tentação em querer generalizar os resultados da pesquisa sobre a questão, em querer transformar tais resultados em modelos operacionais e em propor as abordagens aplicacionistas.

Ora, Bru (1997) lembra-nos que a prática real nunca é plenamente acessível à análise, pois trata-se de um conjunto de atividades gestuais e de discursos operatórios singulares e complexos (constituídos de numerosas dimensões interconectadas) (Altet, 2002), em situação, ancorados na imediaticidade do cotidiano, antes (fase pré-ativa), durante (fase interativa) e depois da ação (fase pós-ativa) (Altet, 2002; Bru \& Talbot, 2001). O acesso cognitivo à pratica é ainda mais difícil pois, como o coloca em destaque Schutz (1987), "somente o ator sabe quando sua ação começa e quando ela termina” (p. 31). O significado da ação varia em função do seu autor, do contexto no qual ela acontece, dos sujeitos da intervenção e do observador. Este último, esteja no papel de formador ou de pesquisador, tem acesso somente a alguns fragmentos manifestos na ação, aos quais ele aplica sua grade de leitura. Assim, Bru (2002b) afirma a necessidade de tornar lúcidas as relações entre os saberes produzidos pela pesquisa e os saberes emergidos da prática, colocando como base para uma tal confrontação "o reconheci- 
mento de uma autonomia irredutível da prática" (p. 136), em virtude de suas características singulares, pontuais, complexas, contextualizadas, múltiplas e interdependentes. Além disso, o efeito-mestre sobre os processos de aprendizagem deve ser considerado "como o produto de uma interação" (Bressoux, 2001, p. 42) entre os alunos e o professor no seio de uma situação de aprendizagem e não como o único resultado das características pessoais do professor. À guisa de síntese, será ilusório acreditar numa transferência aplicacionista dada a impossibilidade de neutralização do conjunto das variáveis individuais, coletivas e contextuais que intervêm na prática e dada a necessidade de identificar os tipos de experiência que favorecem o desenvolvimento da especialização docente.

Mas de forma alguma esta constatação exime a pesquisa de se esforçar em modelizar, por meio da racionalização científica, as práticas docentes de maneira que melhor as descreva e que mais bem as compreenda. Como Popper (1982) destaca, o empirismo estrito não conduz à certeza. Do particular não se pode concluir o universal. A acumulação de fatos e de exemplos nunca se constituirá numa garantia de verdade absoluta. Os fatos repetidos só podem conduzir o pesquisador a inferir uma constante hipotética. Repetição não é razão! Como o uso exacerbado de questionários e de entrevistas (Bressoux, 1994; DuruBellat \& Leroy-Audoin, 1990) só permitiu obter o discurso dos professores sobre as suas próprias práticas docentes e não as suas práticas reais (Bressoux, 2001), faz-se mister o confronto entre as práticas declaradas e as práticas efetivas. Bressoux (2001) sublinha que as observaçōes diretas da fase interativa da prática docente apresentam também vários limites (modificações em razão da presença do observador, dificuldades de realizar observações longas e/ou numerosas etc.). Além disso, se a observação direta se apresenta como a via privilegiada para o estudo das práticas docentes efetivas, é importante estar consciente de que as práticas observadas não são sempre assimiláveis às práticas habituais de um professor; trata-se apenas de práticas constatadas sob condições de observação (Bru, 2002b). É aqui que, além da necessidade de maior prudência da parte do pesquisador, salta-nos aos olhos a importância de utilizar métodos mistos que permitam, por seus diferentes dispositivos de coleta e de tratamento de dados, cruzar os resultados com uma maior chance de focalizar as características subjacentes às práticas. 


\section{Conclusão}

Se entendemos que as práticas de formação docente devem abandonar as posturas prescritivas, descendentes e impositivas que buscam dizer e impor a verdade (como se deve ensinar, como ter práticas eficazes, como ser um bom professor etc.), devemos mais do que nunca partir da prática efetiva que acontece cotidianamente nas salas de aula e não de uma idéia preconcebida daquilo que ela é ou deve ser. É somente pagando este preço que a ação de formação terá influências sobre o agir do professor.

A modelização das práticas - trabalho da pesquisa por excelência - parece-nos indispensável, incontornável, essencial para descrever e caracterizar as práticas docentes, para em conseqüência designar as intervençōes de formação e elaborar diretrizes para a ação. Entretanto, é importante estar consciente de que, no diálogo estabelecido entre o pesquisador e o professor formador e entre este e o professor, toda a dinâmica das relações está sempre a ser (re)construída em função dos modelos construídos, o mais próximo da realidade, pois não é pemitido confundir o agir singular e as particularizações que possibilitam a modelização. E este problema subsiste mesmo se - e talvez ainda mais em decorrência das dificuldades de distanciação - somos ao mesmo tempo pesquisadores e formadores.

Recebido em março de 2006 e aprovado em maio de 2006.

\section{Notas}

1. Agradecemos a Anderson Araújo Oliveira, estudante do programa de Dotourado em Educação da Universidade de Sherbrooke, pela tradução em português do presente artigo.

2. Tradução livre de: Que sont mes amis devenues/ Que javais de si près tenu/ Et tant aimés?/ Je crois qu'ils sont trop clairsemés/ (...) Je crois le vent les m'a ôtés./ L'amour est morte:/ Ce sont amis que vent emporte,/ Et il ventait devant ma portel Les emporta (...).

3. Assim como nós já havíamos mencionado (Lenoir, 1975), "a teoria, entendida como um conjunto logicamente coerente de instrumentos de análise da realidade construída de forma abstrata, mesmo a partir de uma abordagem indutiva, dá à luz diversos modelos, isto é, corpos de proposiçóes estritamente formalizados que se referem a um aspecto específico da teoria. Se um modelo consiste em uma forma heurística elaborada tendo em vista oferecer uma interpretação particular de uma teoria, os diferetnes modelos, que são suscitados para resolver enigmas precisos do conjunto teórico e que se diferenciam entre eles por sua construção formal, apóiam-se no entanto nas bases teóricas (leis gerais, regras normativas, metodologia e maneira de explorar as técnicas etc.) e possuem relaçóes 
Pesquisar e formar: repensar o lugar e a função da prática de ensino

conceituais fundamentais" (p. 49). É geralmente neste sentido que o termo é utilizado pela pesquisa científica: "Expressão de uma teoria ou abstração de uma teoria. É uma representação funcional da realidade, um processo de abstração que contribui a representar de forma mais simples uma realidade sempre complexa" (Ouellet, 1994, p. 258). Se, como remarca Simon \& Newell (1956), a noção de modelo pode ser tomada freqüentemente como um sinônimo de "teoria" - como é o sentido tomado aqui -, ela se refere igualmente, em função das abordagens epistemológicas normativas tradicionais, à idéia de referência ideal a atingir (Legendre, 1993). Então, o modelo traduz uma idealização de uma realidade amplamente conotada por valores morais, por opçôes ideológicas, culturais, políticas, econômicas etc.: "Ele implica recorrer à imitação que assegura a obtenção de uma cópia perfeita (como a cópia do falsário) ou a assimilação do conjunto das características a se apropriar para chegar a um estado de perfeição que ele pretende exprimir (por exemplo, o modelo do homem honesto, da atitude cultivada, de um ideal de beleza feminina, de santidade etc.). Mas um modelo pode também significar o original (o modelo do pintor), o protótipo ou a maquete de um objeto ou de uma máquina, o modelo reduzido ou ainda o esqueleto de um discurso" (Lenoir et al., 1992, p. 7-8).

\section{Referências bibliográficas}

ADEY, P. et al. The professional development of teachers: practice and theory. Dordrecht: Kluwer, 2004.

ALTET, M. Les dispositifs d'analyse des pratiques pédagogiques en formation d'enseignants: une démarche d'articulation pratique-théoriepratique. In: Blanchard-Laville, C.; Fablet, D. (Org.). L'analyse des pratiques professionnelles. Paris: l'Harmattan, 2000. p. 15-34.

ALTET, M. Une démarche de recherche sur la pratique enseignante: l'analyse plurielle. Revue Française de Pédagogie, Paris, n. 138, p. 85-93, 2002.

BAYER, E. Une science de l'enseignement est-elle possible? In: CRAHAY, M.; Lafontaine, D. (Org.). L'art et la science de l'enseignement. Bruxelles: Labor, 1986. p. 483-507.

BAUDOUIN, J.-M.; FRIEDRICH, J. Théories de l'action et éducation. In: Baudouin, J.-M.; Friedrich, J. (Org.). Théories de l'action et éducation. Bruxelles: De Boeck, 2001. p. 7-24.

BEILLEROT, J. La "recherche", essai d'analyse. Recherche et Formation, Paris, n. 9, p. 17-31, 1991.

BORKO, H. Professional development and teacher learning: mapping the terrain. Educational Researcher, Washington, DC, v. 8, n. 33, p. 3-15, 2004 . 
BRESSOUX, P. Estimer et expliquer les effets des classes: le cas des acquisitions en lecture. Mesure et Evaluation en Education, Paris, v. 1, n. 17, p. 75-94, 1994.

BRESSOUX, P. Réflexions sur l'effet-maître et l'étude des pratiques enseignantes. Les Dossiers des Sciences de l'Education, Toulouse, n. 5, p. 35-52, 2001.

BRU, M. Connaître l'acte d'enseigner. Sherbrooke: Université de Sherbrooke; Faculté d'Education, 1997. (mimeo)

BRU, M. Savoirs de la recherche et savoirs des praticiens de l'enseignement: jeu de dupes ou rencontre ouverte et constructive? In: Donnay, J.; BRU, M. (Org.). Recherches, pratiques et savoirs en éducation. Bruxelles: De Boeck, 2002a. p. 133-154.

BRU, M. Pratiques enseignantes: des recherches à conforter et à développer. Revue Française de Pédagogie, Paris, n. 138, p. 63-73, 2002b.

BRU, M.; TALBOT, L. Les pratiques enseignantes: une visée, des regards. Les Dossiers des Sciences de l'Education, Toulouse, n. 5, p. 9-33, 2001 .

BRYMAN, A. The debate about quantitative and qualitative research: a question of method or epistemology? British Journal of Sociology, London, n. 35, p. 78-92, 1984.

CATZ, T. La diffusion des résultats de la recherche en éducation. Revue Française de Pédagogie, Paris, n. 77, p. 109-116, 1986.

CHI, M.T.H. Quantifying qualitative analyses of verbal data: a practical guide. Journal of the Learning Sciences, Mahwah, NJ, v. 3, n. 6, p. 271-315, 1997.

CRAHAY, M. Contraintes de situation et interactions maître-élève: changer sa façon d'enseigner, est-ce possible? Revue Française de Pédagogie, Paris, n. 88, p. 67-94, 1989.

CRESWELL, J.W. Research design: qualitative, quantitative, and mixed methods approaches. Thousand Oaks: Sage, 2002.

CUBAN, L. How teachers tought: constancy and change in American classrooms, 1890-1980. New York: Longman, 1984.

Educ. Soc., Campinas, vol. 27, n. 97, p. 1299-1325, set./dez. 2006 
DE BRUYNE, P. Politique de la connaissance: analyse des enjeux et décisions. Bruxelles: De Bœck, 1988.

DE BRUYNE, P.; HERMAN, J.; DE SCHOUTHEETE, M. Dynamique de la recherche en sciences sociales: les pôles de la pratique méthodologique. Paris: Presses Universitaires de France, 1974.

DESGAGNÉ, S. Le concept de recherche collaborative: l'idée d'un rapprochement entre chercheurs universitaires et praticiens enseignants. Revue des Sciences de l'Education, Montréal, v. 23, n. 2, p. 371-394, 1997.

DESGAGNÉ, S. La position du chercheur en recherche collaborative: illustration d'une démarche de médiation entre culture universitaire et culture scolaire. Recherches Qualitatives, Trois-Rivières, n. 18, p. 371393, 1998.

DESGAGNÉ et al. L'approche collaborative de recherche en éducation: un rapport nouveau à établir entre recherche et formation. Revue des Sciences de l'Education, Montréal, v. 27, n. 1, p. 33-64, 2001.

DOYLE, W. Paradigmes de recherche sur l'efficacité des enseignants. In: Crahay, M.; Lafontaine, D. (Org.). L'art et la science de l'enseignement. Bruxelles: Labor, 1986. p. 435-481.

DUNKIN, M.J. Concepts et modèles dans l'analyse des processus d'enseignement. In: CrahaY, M.; Lafontaine, D. (Org.). L'art et la science de l'enseignement. Bruxelles: Labor, 1986. p. 39-80.

DURU-BELLAT, M.; LEROY-AUDOIN, C. Les pratiques pédagogiques au CP: structure et incidence sur les acquisitions des élèves. Revue Française de Pédagogie, Paris, n. 93, p. 5-15, 1990.

FERRÉOL, G.; DEUBEL, P. Méthodologie des sciences sociales. Paris: Armand Colin, 1993.

FREITAG, M. Dialectique et société. Montréal: Saint-Martin, 1986. t.1

GAGE, N.G. Comment tirer un meilleur parti des recherches sur les processus d'enseignement. In: Crahay, M.; Lafontaine, D. (Org.). L'art et la science de l'enseignement. Bruxelles: Labor, 1986. p. 411-433.

GÉLINAS, A.; PILON, J.-M. Le transfert des connaissances en recherche sociale et la transformation des pratiques sociales. Nouvelles Pratiques Sociales, Québec, v. 2, n. 7, p. 75-91, 1994. 
GLASSER, E.M.; ABELSON, H.H.; GARRISON, K.N. Putting knowledge to use. San Francisco: Jossey-Bass, 1983.

GOULDNER, A. The coming crisis of western sociology. New York: Avon Books, 1971.

GUEORGUIEVA, V. La connaissance de l'indéterminé: le sens commun dans la théorie de l'action. 2004. Tese (Doutorado) - Faculté des Sciences Sociales, Université Laval, Québec.

HOUSE, E.; MATHISON, S.; McTAGGART, R. Validity and teacher inference. Educational Researcher, Washington, DC, v. 7, n. 18, p. 11-15, 1989.

HOWE, K.R. Getting over the quantitative-qualitative debate. American Journal of Education, Chicago, n. 100, p. 236-256, 1992.

HUBERMAN, M. Steps toward an integrated model of research utilization. Knowledge: Creation, Diffusion, Utilization, Thousand Oaks, v. 4, n. 8, p. 586-611, 1987.

HUBERMAN, M. Predictor of conceptual effects in research utilization. Knowledge in Society, v. 3, n. 2, p. 6-24, 1989.

HUBERMAN, M. Linkage between researchers and practitioners: a qualitative study. American Educational Research Journal, Washington, DC, v. 2, n. 27, p. 363-391, 1990.

HUBERMAN, M.; GATHER THURLER, M. De la recherche à la pratique: éléments de base. Berne: Peter Lang, 1991.

JOHNSON, R.B.; ONWUEGBUZIE, A.J. Mixed methods research: a research paradigm whose time has come. Educational Researcher, Washington, DC, v. 7, n. 33, p. 14-26, 2004.

KAESTLE, C.F. The awful reputation of education research. Educational Researcher, Washington, DC, v. 1, n. 22, p. 23-31, 1993.

KARSENTI, T.; SAVOIE-ZAJC, L. (Org.). Introduction à la recherche en éducation. Sherbrooke: CRP, 2000.

LEFRANÇOIS, R. Stratégies de recherche en sciences sociales: applications à la gérontologie. Montréal: Université de Montréal, 1992.

Educ. Soc., Campinas, vol. 27, n. 97, p. 1299-1325, set./dez. 2006 
Pesquisar e formar: repensar o lugar e a função da prática de ensino

LEGENDRE, R. Dictionnaire actuel de l'éducation. 2. ed. Montréal: Guérin, 1993.

LENOIR, Y. Essai d'élaboration d'un schéma théorique d'analyse du processus éducatif scolaire. 1975. Dissertação (Mestrado) - Université du Québec, Montréal.

LENOIR, Y. Pour une collaboration tripartite dans une perspective de recherche action. In: LeNOIR, Y.; LAFOREST, M. (Org.). L'enseignement des sciences humaines au primaire: développement, sous-développement ou développement du sous-développement? Sherbrooke: CRP, 1991. p. 165-175.

LENOIR, Y. Entre Hegel et Descartes: de quels sens peut-il être question en didactique? In: JonnaerT, P.; Lenorr Y. (Org.). Sens des didactiques et didactique du sens. Sherbrooke: CRP, 1993. p. 29-99.

LENOIR, Y. La recherche collaborative, les facultés d'éducation, le milieu scolaire et les organismes subventionnaires: un concept à clarifier, une situation fragile, des rapports interinstitutionnels précaires! In: LENOIR, Y.; LAFOREST, M. (Org.). La bureaucratisation de la recherche en éducation et en sciences sociales: constats, impacts et conséquences. Sherbrooke: CRP, 1996. p. 205-232.

LENOIR, Y. et al. Linterdisciplinarité pédagogique au primaire: étude de l'évolution des représentations et des pratiques chez des titulaires du premier cycle du primaire dans le cadre d'une recherche-actionformation. Relatório de pesquisa 3: Modalités et instruments de supervision utilisés. Sherbrooke: GRIDD, Faculté d'Education, Université de Sherbrooke, 1992.

MARCEL, J.-F. et al. Les pratiques comme objet d'analyse; note de synthèse. Revue Française de Pédagogie, Paris, n. 138, p. 135-170, 2002.

MUNBY, H.; RUSSELL, T.; MARTIN, A.K. Teachers' knowledge and how it develops. In: Richardson, V. (Org.). Handbook of research on teaching. Washington, DC: American Educational Research Association, 2001. p. 877-904.

OUELLET, A. Processus de recherche: Une introduction à la méthodologie de la recherche. 2. ed. Sainte-Foy: Université du Québec, 1994. 
POPPER, P. La connaissance objective. Bruxelles: Complexe, 1982.

RICHARDSON, V. Conducting research on practice. Educational Researcher, Washington, DC, v. 5, n. 23, p. 5-10, 1994.

SCHUTZ, A. Le chercheur et le quotidien: phénoménologie des sciences sociales. Paris: Méridiens Klincksieck, 1987.

SHAFFER, D.W.; SERLIN, R.C. What good are statistics that don't generalize? Educational Researcher, Washington, DC, v. 9, n. 33, p. 14-25, 2004.

SIMON, H.A.; NEWELL, A. Models: their uses and limitations. In: White, L. (Org.). The state of the social sciences. Chicago: University of Chicago, 1956. p. 66-83.

SPENCER, D.A. Teacher's work in historical and social context. In: Richardson, V. (Org.). Handbook of research on teaching. Washington, DC: American Educational Research Association, 2001. p. 803-825.

TARDIF, M. et al. Savoirs professionnels et formation à l'enseignement. In: Lenoir, Y.; Hunter, W.; Hodgkinson, D.; De Broucker, P.; Dolbec, A. (Org.). A pan-Canadian education research agenda: un programme pancanadien de recherche en éducation. Ottawa: Canadian Society for Studies in Education, 2000. p. 91-119.

TASHAKKORI, A.; TEDDLIE, C. Mixed methodology: combining qualitative and quantitative approaches. Thousand Oaks: Sage, 1998.

TASHAKKORI, A.; TEDDLIE, C. Handbook of mixed methods in social and behavioral research. Thousand Oaks: Sage, 2003.

VANHULLE, S.; LENOIR, Y. L'état de la recherche sur la formation à l'enseignement. Sherbrooke: CRP, 2005. 